\title{
Formas plurais no setor de distribuição de combustível automotivo brasileiro: avaliação do perfil e estabilidade das governanças plurais no Estado de São Paulo
}

\section{Plural forms in the Brazilian automotive fuel distribution sector: profile evaluation and plural governances stability in São Paulo State}

\author{
Selene de Souza Siqueira Soares ${ }^{1}$ \\ Maria Sylvia Macchione Saes ${ }^{2}$ \\ Luiz Fernando de Oriani e Paulillo ${ }^{3}$
}

\begin{abstract}
Resumo: $\mathrm{O}$ trabalho se dedica ao estudo das governanças das transações adotadas pelas distribuidoras de combustíveis no Estado de São Paulo com os postos revendedores varejistas. A partir da desregulamentação do mercado, formas plurais foram permitidas e têm sido recorrentes no mercado. Neste artigo, argumenta-se que as formas plurais encontradas são transitórias, mas que isso não se dá em razão de aumento da eficiência e redução de custos de transação, mas sim pela forma plural ter se tornado um passo estratégico fundamental para alcançar parceiros comerciais e promover maior crescimento da firma. Ademais, argumenta-se que o ambiente institucional apresentou influência significativa na coordenação das formas plurais, interferindo diretamente na estabilidade destas.

Palavras-chave: Formas plurais; Economia institucional; Ambiente institucional; Distribuição de combustíveis.
\end{abstract}

\begin{abstract}
This paper aims to study the governance of transactions adopted by fuel distributors with gas station retailers in the state of São Paulo. With the market deregulation, there are plural forms allowed on the market. This paper argues that the plural forms found are transitory, not as a result of increased efficiency and reduced transaction costs, but because plural forms have become a key strategic step in securing business partners and promoting greater growth of the firm. Moreover, it is argued that the institutional environment has a significant influence on the coordination of plural forms, directly interfering with their stability.
\end{abstract}

Keywords: Plural forms; Institutional economics; Institutional environment; Fuel distribution.

\section{Introdução}

Até o início dos anos noventa, a distribuição de combustíveis no Brasil era fortemente conduzida pelo governo. Operavam no mercado poucas empresas distribuidoras autorizadas e era mantido o monopólio estatal da Petrobras na produção e distribuição de combustível. Além disso, o governo mantinha preços tabelados em todos os elos da cadeia. A partir de 1997, o governo ampliou as medidas liberalizantes no setor, com o objetivo principal de promover o aumento da competitividade. Houve o fim do monopólio estatal, fim do tabelamento de preços e a permissão da entrada de novas firmas no mercado nacional e da importação de combustíveis.

Uma das mais importantes alterações no funcionamento deste mercado foi a alteração no modelo de revenda de combustíveis. Até 1997, os postos eram obrigatoriamente atrelados aos distribuidores, dos quais exibiam as marcas, atuando no mercado como unidades de franquia. Desta forma, as transações dos distribuidores com postos se davam por contratos de fidelidade e exclusividade de negociação.

\footnotetext{
${ }^{1}$ Departamento de Engenharia de Produção e Sistemas, Centro Técnológico, Universidade Federal de Santa Catarina - DEPS/UFSC, Campus Universitário, Rua Engenheiro Agronômico Andrei Cristian Ferreira, s/n, Trindade, CEP 88040-900, Florianópolis, SC, Brasil, e-mail: selene.soares@ufsc.br

${ }^{2}$ Faculdade de Economia, Administração e Contabilidade - FEA, Universidade de São Paulo - USP, Av. Prof. Luciano Gualberto, 908, Sala 16 C, Cidade Universitária, Butantã, CEP 05508-010, São Paulo, SP, Brasil

${ }^{3}$ Departamento de Engenharia da Produção - DEP, Centro de Ciências Exatas e de Tecnologia, Universidade Federal de São Carlos - UFSCar, Rodovia Washington Luis, Km 235, Área norte, CEP 13565-905, São Carlos, SP, Brasil
}

Recebido em Abr. 15, 2014 - Aceito em Jun. 30, 2015

Suporte financeiro: FAPESP (Fundação de Amparo à Pesquisa do Estado de São Paulo). 
A partir da desregulamentação, uma nova modalidade foi permitida quando instituiu postos sem contratos de fornecimento com a distribuidora, operando como um posto "sem marca" por não ser franqueado de nenhuma distribuidora. Esta categoria se convencionou chamar de "postos de bandeira branca" ou sem marca. Como esperado, o perfil da revenda mostrou um aumento expressivo no número de postos de bandeira branca, chegando a mais de $40 \%$ do total das unidades de revenda atualmente (ANP, 2013).

A inserção desta nova modalidade de revenda abriu espaço no mercado para a pluralidade das transações nas distribuidoras, na medida em que as distribuidoras podem agora escolher manter dois modos de escoamento da produção alternativos:

1) Modelo contratual, semelhante a uma franquia, com postos com contratos de exclusividade. Esta transação exige investimentos em ativos específicos de lay out e normalização do ponto de venda e da atividade assim como numa franquia, em que há um "modus operandi" a ser seguido. Estes custos normalmente são de responsabilidade da empresa distribuidora.

2) Vendas esporádicas, para postos com os quais não se tem contrato de fornecimento exclusivo. Nestas transações não há investimento em ativos específicos ao negócio. Estas serão tratadas aqui, com certa liberalidade semântica apenas como "Mercado".

Do ponto de vista da pesquisa acadêmica, tornou-se interessante avaliar de que modo o mercado distribuidor se ajustou à alteração na legislação, quando esta passou a permitir governanças plurais. E assim, o interesse da pesquisa é destacar algumas questões fundamentais como: Todos os distribuidores passaram a atuar de forma plural quando a legislação permitiu? Se não, que tipo de distribuidora é plural? O que justifica adoção desta forma de governança? A manutenção da forma plural no mercado é estável ou transitória? Qual o impacto do ambiente institucional na definição dos arranjos de escoamento de produção das firmas distribuidoras?

Em resumo, o presente estudo busca entender o comportamento das formas plurais neste mercado, avaliando, ao longo dos últimos quinze anos, qual a tendência de estabilidade destes arranjos. No plano teórico, a análise se sustenta nos trabalhos recentes que discutem a motivação para o uso de formas alternativas de governança, ressaltando que, em alguns mercados em que há elevado grau de incerteza devido à dificuldade de mensuração da qualidade, a tendência será do desaparecimento das relações de "mercado" e, por conseguinte, das formas plurais. Há diferentes explicações para o surgimento dessas formas plurais e fornecem explicações alternativas quanto à sua estabilidade no longo prazo (Arthur, 1989, 1994; Lafontaine \& Shaw (2005), Azevedo \& Silva, 2012; Bradach \& Eccles, 1989; Carlton, 1979; Michael, 2000; Heide, 2003; Schnaider, 2011; Mols et al., 2012).

Neste sentido, a argumentação principal do artigo é de que uma das razões para adoção de formas plurais é a possibilidade de que tal forma represente um movimento estratégico que permita o crescimento da firma a longo prazo. Embora o argumento tenha características de transitoriedade, acredita-se que o movimento transitório possa se perpetuar por um longo tempo, mantendo a estabilidade da adoção das formas plurais, embora não com os mesmos agentes. Pretende-se, portanto, a realização de um estudo empírico que venha somar resultados objetivos a esta área, dento dos estudos de economia institucional.

O método de pesquisa utilizado foi a realização de entrevistas presenciais, com aplicação de questionário estruturado a 25 empresas distribuidoras atuantes no Estado de São Paulo, as quais respondem por aproximadamente $80 \%$ das vendas nacionais de gasolina e etanol. As informações tratadas neste estudo fazem parte de uma base de dados mais ampla de projeto de pesquisa anterior, Soares (2012). A concentração no Estado de São Paulo se justifica por ser o maior mercado brasileiro de combustível automotivo, concentrando $25 \%$ dos postos revendedores de combustíveis do País, e a venda de mais de $30 \%$ da gasolina e $60 \%$ do etanol automotivos consumidos nacionalmente (ANP, 2013).

O artigo possui quatro sessões além desta introdução. Na segunda sessão, é feita a revisão teórica acerca das formas plurais e a discussão sobre sua estabilidade ou não, privilegiando abordagem de Economia Institucional. No terceiro tópico, é feito um breve histórico do setor estudado, privilegiando as alterações recentes, após a desregulamentação. Na quarta sessão, são descritos as evidências empíricas das formas plurais na distribuição de combustíveis e o impacto do ambiente institucional nesses arranjos. Por fim, a última sessão trata das discussões finais do trabalho.

\section{Abordagem teórica}

O uso simultâneo de mais de uma estrutura de governança para reger o relacionamento das firmas com seus parceiros, seja para suprimento seja para comercialização e escoamento de produtos, é considerado forma plural. Encontram-se na literatura diferentes terminologias empregadas na discussão sobre essa pluralidade, tais como 'mix contratual' (Bai \& Tao, 2000; Azevedo \& Silva, 2012), 'formas plurais' (Bradach \& Eccles, 1989; Bradach, 1997; Coughlan et al., 2002), 'distribuição dual' (Bai \& Tao, 2000), 'fornecimento concomitante (Parmigiani, 2007; 
Mols, 2010), 'tappered integration', dentre outras. Em comum, todas estas abordagens consideram que uma empresa é plural sempre que utilizar mais de uma estrutura de governança para estruturar suas transações com idênticas características. A discussão sobre o que motiva tal decisão tem sido recorrente na literatura.

$\mathrm{Na}$ tentativa de explicar os motivadores de tais escolhas, diferentes enfoques teóricos relacionam a manutenção de formas plurais a uma série de variáveis ligadas à eficiência, à necessidade de monitoramento e controle dos parceiros da cadeia de valor e à capacidade de inovar e obter conhecimento no ambiente de franquias.

A abordagem clássica de economia de custos de transação admite que as formas plurais são transitórias. A partir dos atributos das transações (incerteza, frequência e especificidade de ativos) haveria um alinhamento ótimo e único destes com a estrutura de governança eficiente, minimizadora de custos de transação. A transitoriedade da forma plural seria inevitável na medida em que, ao longo do tempo, os agentes tenderiam a estabelecer a estrutura de governança ótima ao substituir gradualmente os arranjos menos eficientes já utilizados (Arthur, 1989, 1994).

De fato, a observação do funcionamento de vários mercados tem mostrado a recorrência de utilização dos arranjos plurais. Os estudos empíricos sobre este tipo de governança costumam utilizar variáveis dependentes simples para testar a correlação entre variáveis independentes e o uso ou não da forma plural. Desta forma, estabelecem entendimento das características da firma que decide ser ou não plural (por exemplo Parmigiani, 2007; Heide, 2003). Na mesma linha de análise, alguns estudos sobre franquia utilizam esta mesma abordagem, caracterizando diferenças entre firmas que adotam ou não a pluralidade das governanças. Outros estudos multissetoriais têm avançado nos esforços de explicação das motivações para a pluralidade e o que fica claro é que ainda não está consolidada uma tipologia taxativa quanto às motivações possíveis para adoção das formas plurais.

Neste sentido, a argumentação principal do artigo é de que uma das razões para a adoção de formas plurais é a possibilidade de que tal forma represente um movimento estratégico que permita o crescimento da firma a longo prazo. Embora o argumento tenha características de transitoriedade, acredita-se que o movimento transitório possa se perpetuar por um longo tempo, mantendo a estabilidade da adoção das formas plurais, embora não com os mesmos agentes.

\section{Breve histórico do setor}

Na década de noventa, os modelos de condução da política econômica brasileira apresentaram inclinação evidente à mudança do papel do Estado de produtor para regulador. Neste contexto, o setor de distribuição de combustíveis também foi alcançado por leis que derrubaram a exclusividade estatal na produção e distribuição e permitiu a entrada de novas concorrentes no setor (Marjotta-Maistro, 2002).

O mercado de combustíveis no Brasil passou a ser regulamentado pela Lei 9.478/97. Esta lei flexibilizou o monopólio do setor petróleo e gás natural, até então exercido pela Petrobras, e liberou as importações de gasolina e o preço do produtor rural em janeiro de 2002 , bem como interrompeu a política de tabelamento de preços dos combustíveis.

O processo de desregulamentação tinha como objetivo principal o aumento da competição no setor a partir de duas alterações fundamentais: o fim do fornecimento exclusivo aos postos, com a permissão dos postos sem contratos de fornecimento com o distribuidor e a permissão da entrada de novas distribuidoras e importadoras no mercado.

A lei que hoje regulamenta o setor ainda estabeleceu que o mercado atacadista (upstream) ficaria restrito às distribuidoras, enquanto o mercado varejista (downstream), restrito aos postos revendedores. Ou seja, a lei vetou aos postos a aquisição direta de usinas, refinarias, formuladores, petroquímicas ou importadores e também vetou ao distribuidor de combustíveis líquidos de petróleo, etanol e outros combustíveis automotivos o exercício da atividade de revenda varejista.

Adicionalmente, a portaria ANP n ${ }^{\circ} 116 / 2000$ instituiu que os postos de combustíveis somente podem comprar combustíveis das distribuidoras com as quais mantêm contratos de fornecimento e bandeiramento, exceto os postos de "bandeira branca" que podem comprar de qualquer distribuidora. Fica a critério do proprietário do posto a decisão de estar atrelado a uma marca da distribuidora com a qual negocia exclusivamente ou se manter desvinvulado de qualquer distribuidora e poder negociar com qualquer distribuidor.

Ao proibir a integração vertical e instituir a obrigatoriedade da exclusividade de negociação dado o bandeiramento do posto, o aparato legal vigente definiu a existência de formas organizacionais com e sem contratos, criando arranjos de negociação exclusivas. Neste contexto, as mudanças no ambiente legal, tornaram cada vez mais complexas as relações entre postos varejistas e distribuidoras (Mahoney, 1992; Lal, 1990).

Como resultado destas imposições legais, há, basicamente, três tipos de distribuidores em atuação no mercado:

- Distribuidores Dominantes: Distribuidoras tradicionais, já em atuação no mercado antes do processo de desregulamentação do setor, possuem alta participação no mercado nacional, acima de $15 \%$; e possuem marcas de franquia de abrangência nacional. 
- Distribuidores Regionais: Distribuidoras que ingressaram no mercado nacional a partir da desregulamentação do setor em 1997; possuem baixa participação no mercado nacional, abaixo de $7 \%$; e possuem marcas de franquia de abrangência regional.

- Distribuidores Independentes: Distribuidoras que ingressaram no mercado nacional a partir da desregulamentação do setor em 1997; apresentam participação muito baixa no mercado nacional, abaixo de $2 \%$; e não possuem marcas de franquia.

Por meio de arranjos com contratos, as distribuidoras mantêm canal exclusivo de vendas, fazem a cessão de suas marcas e, em regime de comodato, ativos físicos específicos como adequação de layout, tanques e bombas. Segundo Hart \& Moore (1990), cedendo esses ativos em regime de comodato, as distribuidoras obtêm o direito residual de decisão ou controle, que são direitos para decidir sobre contingências futuras não previstas nos contratos.

Já nos arranjos sem contrato, o investimento para montagem do negócio passa a ser exclusivo do posto revendedor, contando, de um lado, com a total liberdade de negociação com diferentes fornecedores e condução dos negócios e, de outro, deixando de contar com o apelo de marca junto a seus clientes.

De modo geral, quer nos arranjos com contratos, quer naqueles sem contrato, todas estas modificações na configuração da indústria resultaram em desgaste da relação entre as empresas distribuidoras e os postos revendedores de combustíveis. Segundo Moraes (2004), a turbulência provocada pela desregulamentação pôde ser percebida por ambos os atores. Para as empresas distribuidoras, a desregulamentação significou o fim do oligopólio, enquanto para os postos revendedores significou o acirramento da competição com a queda do regime de concessão para abertura de postos e a queda das margens de revenda em função da proliferação dos produtos adulterados e sonegados.

De um lado, as empresas distribuidoras culparam seus postos pela queda nas vendas, pela infidelidade ao adquirir produtos de outras distribuidoras, pela ineficiência em fazer o consumidor final perceber o valor de suas bandeiras (que deveria ser suficiente para compensar a diferença de preço praticada pelos postos bandeiras brancas) e pela ineficiência em gerir os postos com margem menor, sendo capazes de otimizar seus custos. Do outro lado, os postos culparam as empresas distribuidoras pela falta de competitividade em relação ao mercado irregular, pela diferença de preços praticada para sua rede de postos, pela falta de influência junto aos órgãos competentes pela fiscalização do setor e pela falta de flexibilidade para atender a situações emergenciais de crédito.

Como resultado, o fato é que a desregulamentação redefiniu as bases competitivas do setor, sendo percebida uma queda no desempenho tanto das distribuidoras quanto dos postos, que somente tem sido compensada pelo aumento nas vendas. Para tal, novas estratégias e modelos de negócios tem sido adotados (Moraes, 2004; Nunes \& Gomes, 2005; Medeiros, 2007; Soares \& Paulillo, 2011).

\subsection{Alterações no ambiente institucional}

Depois da desregulamentação do setor, o ambiente institucional alterou-se drasticamente. A lei do petróleo de 1997 criou a Agência Nacional do Petróleo, Gás Natural e Biocombustíveis (ANP). A ANP é uma autarquia especial vinculada ao Ministério de Minas e Energia, com a finalidade de promover a regulação e a fiscalização das indústrias do petróleo, do gás natural e dos biocombustíveis, incentivando a livre concorrência e o desenvolvimento nacional com foco no interesse público e na preservação do meio ambiente.

A atuação da agência tem se ampliado progressivamente, especialmente nas questões de fiscalização do setor. Especialmente no elo distribuidor varejista, a atuação da agência apresenta-se mais evidente nas fiscalizações relacionadas à qualidade dos combustíveis vendidos e adequação destes à legislação; no levantamento de preços e margens de comercialização para avaliação de práticas de cartel e também nas fiscalizações relacionadas à garantia da fidelidade do posto revendedor ao seu arranjo exclusivo de negociação; o que inclui, dentre outras coisas, maior controle também das firmas distribuidoras e das usinas de etanol, que ficam impedidas de fornecer o combustível direto aos postos.

De fato, a permissão da entrada de novas firmas no mercado e a falta de um aparato institucional regulador anterior fez com que houvesse no mercado nacional grande descontrole quanto aos padrões de qualidade e responsabilidade fiscal das firmas no segmento. Uma série de escândalos e denúncias sobre adulteração de combustíveis, contrabando, sonegação fiscal e práticas ilegais de toda ordem inundaram o mercado.

Em resposta a estes acontecimentos, do ponto de vista normativo, severas alterações foram realizadas no setor, com especial destaque para: a) inserção de marcadores aos solventes para facilitar a identificação de adulteração de gasolina; b) inserção de marcadores ao etanol anidro para facilitar a identificação de adulteração etanol; c) aumento da fiscalização das usinas de etanol, o que reduziu o comércio de etanol irregular de mais de $35 \%$, no início dos anos 2000 , para 12\%, em 2013 (Etanol vendido diretamente 
das usinas para os postos de combustível sem passar pela distribuidora); d) Início de fiscalização no elo upstream: distribuidoras e usinas de biocombustível no que se refere à qualidade; e) início da fiscalização quanto à fidelidade dos postos de combustíveis e cumprimento do arranjo exclusivo de negociação e procedência dos combustíveis.

Juntamente com isso, os programas de fiscalização por parte da Receita Federal, com destaque para o Estado de São Paulo, com a criação de programas específicos de combate à ilegalidade no setor e os programas da Secretaria da Fazenda, também têm contribuído para disciplinar e fazer valer as regras definidas no processo de desregulamentação.

Do ponto de vista competitivo, embora a política pública de desregulamentação tivesse como objetivo principal o aumento da competição no setor, o que ocorreu foi exatamente o contrário, um expressivo aumento da concentração do mercado distribuidor. Entre os anos de 2005 e 2013, os índices de concentração de mercado da gasolina e etanol passaram de 50,6 e 41,52 para 65,8 e 56,9, na observação do CR3, e de 0,115 e 0,074 para 0,157 e 0,114 do HHI, no mesmo período para os dois combustíveis, respectivamente.

Mais de $20 \%$ das firmas distribuidoras que entraram no mercado nacional de distribuição em fins dos anos noventa saíram do mercado ou foram absorvidas por empresas maiores entre os anos de 2003 e 2013, reforçando o movimento de concentração deste mercado e, também, o impacto das políticas disciplinares no mercado que forçou a saída das firmas que operavam com práticas irregulares.

No elo revendedor varejista, percebe-se também maior concentração de mercado. No início dos anos 2000, o total de postos no Estado de São Paulo a cada 10.000 veículos era superior a 7, atualmente, há, no mercado, pouco mais de 3 postos revendedores a cada 10.000 veículos no estado. Considerando que, no mesmo período, a frota de veículos mais que dobrou de tamanho, o aumento apenas de $10 \%$ na quantidade de unidades de revenda de combustível contribuiu para o aumento das vendas por unidade de revenda, mantendo o mesmo padrão de concorrência. Como não poderia ser diferente, o volume de vendas dos postos praticamente dobrou nos últimos dez anos, conforme se observa na Tabela 1 a seguir.

O perfil de bandeiramento também mudou bastante com incremento progressivo no número de postos de bandeira branca no estado e uma queda no número de postos de bandeiras dominantes e regionais, conforme dados da Tabela 2. Este evento é o que reforça a hipótese do artigo de que forma plural pode funcionar como estratégia de crescimento das firmas distribuidoras, especialmente na retomada da antiga quantidade de unidades de revenda e posterior expansão de mercado, já que se percebe uma forte queda no número de unidades de revenda entre 2000 e 2003, seguida de um movimento de recuperação menos vigoroso a partir de 2004.

Ainda na questão institucional, vale chamar atenção para a construção de reputação dos agentes revendedores. Dadas as profundas transformações neste mercado em pouco tempo, sob a ótica dos consumidores, institucionalizaram-se dois segmentos específicos, os postos de bandeiras dominantes, em que as distribuidoras mantêm expressivo investimento em propaganda para valorização de seus ativos de marca e acabam contando com a maior confiança do consumidor. E os postos de bandeira branca, conhecidos por manter preços mais baixos com qualidade discutível (Soares \& Paulillo, 2011). Entre estes, não se pode esquecer das bandeiras menores - regionais - que ainda buscam a consolidação de suas marcas no mercado, mas, de forma geral, ainda não são reconhecidos pelo mercado consumidor como franquias idôneas,

Tabela 1. Volume de vendas - postos revendedores: gasolina, diesel, etanol e GNV (em bilhões de litros).

\begin{tabular}{lccccccccccc}
\hline $\begin{array}{c}\text { Bandeiramento } \\
\text { do posto }\end{array}$ & $\mathbf{2 0 0 3}$ & $\mathbf{2 0 0 4}$ & $\mathbf{2 0 0 5}$ & $\mathbf{2 0 0 6}$ & $\mathbf{2 0 0 7}$ & $\mathbf{2 0 0 8}$ & $\mathbf{2 0 0 9}$ & $\mathbf{2 0 1 0}$ & $\mathbf{2 0 1 1}$ & $\mathbf{2 0 1 2}$ & $\begin{array}{c}\text { Variação } \\
\text { no período }\end{array}$ \\
\hline Dominantes & 34,7 & 37,3 & 37,5 & 38,9 & 43,7 & 47,5 & 48,9 & 52,7 & 55,7 & 59,7 & $+72,0 \%$ \\
Branca & 13,1 & 14,4 & 14,3 & 15,0 & 16,0 & 18,0 & 19,6 & 21,4 & 21,5 & 23,0 & $+75,6 \%$ \\
Total & 47,8 & 51,7 & 51,8 & 53,9 & 59,6 & 65,5 & 68,5 & 74,1 & 77,2 & 82,7 & $+73,0 \%$ \\
\hline
\end{tabular}

Fonte: SINDICOM (2014).

Tabela 2. Número de postos revendedores no Estado de São Paulo, por bandeira - Anos selecionados.

\begin{tabular}{lccccccc}
\hline $\begin{array}{c}\text { Bandeiramento do } \\
\text { posto }\end{array}$ & $\mathbf{2 0 0 0}$ & $\mathbf{2 0 0 3}$ & $\mathbf{2 0 0 6}$ & $\mathbf{2 0 0 9}$ & $\mathbf{2 0 1 0}$ & $\mathbf{2 0 1 1}$ & $\begin{array}{c}\text { Variação } \\
\text { no período }\end{array}$ \\
\hline Bandeiras Dominantes & 5.586 & 3.504 & 3.922 & 4.134 & 4.257 & 4.276 & $-23,5 \%$ \\
Bandeiras Regionais & 1.466 & 1.237 & 536 & 554 & 639 & 642 & $-56,2 \%$ \\
Bandeira Branca & 826 & 3.195 & 3.946 & 4.129 & 3.863 & 3.880 & $+369,7 \%$ \\
Total & 7.878 & 7.936 & 8.404 & 8.817 & 8.759 & 8.798 & $+11,7 \%$ \\
\hline
\end{tabular}

Fonte: ANP (2013). 
assemelhando-se muito mais com o reconhecimento dado aos postos de bandeira branca.

Nesta questão do apelo de marca, é importante lembrar que o combustível é, na classificação de Barzel (1982), um "bem de crença"; ou seja, quando informações relevantes à transação não são obtidas nem após o consumo do produto. São produtos que possuem características não observáveis diretamente e, nesses casos, a mensuração dos atributos é difícil mesmo após o consumo. Nas transações de tais produtos, a assimetria de informação torna-se um problema custoso e insolúvel e, nesses casos, a marca passa a ser um referencial importante capaz de sintetizar informações importantes na decisão de compra.

Se, de um lado, as grandes marcas das distribuidoras constroem e mantêm elevado ativo de marca, de outro, a instabilidade institucional pós-desregulamentação contribuiu para a percepção de que as irregularidades eram comuns neste mercado e que o segmento de bandeiras brancas era mais suscetível a tais eventos. Não obstante o aumento expressivo da fiscalização e a queda dos índices de não conformidade dos combustíveis em todo o segmento revendedor, esta memória de que se consome combustível de baixa qualidade em postos de bandeira branca ainda persiste.

O Quadro 1 sintetiza as principais mudanças no ambiente institucional e o impacto destes nas formas organizacionais.

\section{Evidências empíricas}

Para tratamento das evidências empíricas das formas plurais no setor, a sessão será subdividida em: descrição do método de pesquisa; caracterização da amostra; uma breve descrição das caracterísiticas das transações e das estrututas de governanças encontratadas; e um último tópico específico sobre as formas plurais observadas.

\subsection{Método de pesquisa}

Neste trabalho, foram realizadas entrevistas presenciais com diretores de empresas distribuidoras de combustíveis automotivos. Os resultados apresentados neste artigo fazem parte de pesquisa de campo realizada por Soares (2012).

Para composição da amostra de empresas de distribuição, foram escolhidas 25 empresas distribuidoras, perfazendo $40 \%$ do total das firmas em atuação no Estado de São Paulo. A seleção de empresas a serem entrevistadas seguiu como critério principal as respectivas participações de mercado. Foram contatadas todas as empresas que detinham mais de $5 \%$ de participação no mercado nacional e as demais, de forma aleatória, tendo como critério secundário a existência de escritório da empresa nos polos petroquímicos visitados: Paulínia, São José dos Campos e Guarulhos.

As entrevistas seguiram uma sequência de perguntas subdivididas em quatro grandes grupos, quais sejam: tópicos relativos às relações com postos de gasolina; os atributos das transações; mecanismos de coordenação; incerteza e comportamentos oportunistas. A definição das perguntas foi feita buscando alinhamento teórico com os principais trabalhos da escola institucionalista utilizados no referencial teórico, a saber: Williamson $(1979,1985$, 1991) e Ménard (2004, 2006).

Quadro 1. Mudanças no ambiente institucional na distribuição de combustível.

\begin{tabular}{|l|l|l|l|}
\hline \multicolumn{1}{|c|}{ Distribuição } & $\begin{array}{c}\text { Antes da desregulamentação } \\
\text { Eovernança } \\
\text { permitidas pela } \\
\text { legislação }\end{array}$ & Revenda Varejista & \multicolumn{1}{c|}{ Ambiente Institucional } \\
\hline $\begin{array}{l}\text { Grandes } \\
\text { Distribuidores }\end{array}$ & - Contratos & $\begin{array}{l}\text { Sempre modo contratual } \\
\text { (Franquia) }\end{array}$ & $\begin{array}{l}\text { - Preços Tabelados } \\
\text { - Pouca/Nenhuma concorrência } \\
\text { - Apelo de marca: Pouca ou nenhuma diferença } \\
\text { entre os distribuidores }\end{array}$ \\
\hline $\begin{array}{l}\text { Grandes } \\
\text { Distribuidores } \\
\text { Distribuidores } \\
\text { Menores }\end{array}$ & \begin{tabular}{l} 
- Fiscalização: Inexistente \\
\hline - Mercado \\
- Plural: Contratos e \\
Mercado
\end{tabular} & $\begin{array}{l}\text { Após a desregulamentação } \\
\text { - Postos de bandeira } \\
\text { (Franca (sem contratos) }\end{array}$ & $\begin{array}{l}\text { - Preços Livres } \\
\text { - Economia aberta } \\
\text { - Concorrência } \\
\text { - Apelo de marca: Muita diferença entre os } \\
\text { distribuidores }\end{array}$ \\
\hline
\end{tabular}

Fonte: Elaboração própria. 


\subsection{Caracterização da amostra}

Considerando as diferenças de porte existentes entre as empresas distribuidoras, os dados pesquisados foram tabulados enquadrando as firmas distribuidoras segundo a classificação adotada no trabalho:

- Distribuidores Dominantes: Distribuidoras tradicionais, já em atuação no mercado antes do processo de desregulamentação do setor; que detêm bandeiras de abrangência nacional, ou seja, possuem pelo menos um posto bandeirado em todos os estados brasileiros; e possuem alta participação no mercado nacional, acima de $15 \%$.

- Distribuidores Regionais: Distribuidoras que ingressaram no mercado nacional a partir da desregulamentação do setor em 1997; que detêm bandeiras de abrangência regional, ou seja, bandeiras concentradas em algumas regiões do País; e possuem baixa participação no mercado nacional, abaixo de $7 \%$.

- Distribuidores Independentes: Distribuidoras que ingressaram no mercado nacional a partir da desregulamentação do setor em 1997; não possuem postos bandeirados; e apresentam muito baixa participação no mercado nacional, abaixo de $2 \%$.

Foram entrevistadas 10 distribuidoras Independentes, 12 Regionais e 3 dominantes. O conjunto de empresas entrevistadas respondem por $72 \%$ das vendas nacionais de etanol e $80 \%$ das vendas nacionais de gasolina. As entrevistas foram realizadas no ano de 2010.

\subsection{Características das transações e estruturas de governança}

Como já descrito anteriormente, basicamente dois tipos de transação são possíveis: transações com contrato e via mercado.

Para efeito de consideração teórica, considera-se a frequência em que se negociam as transações. Nas transações via mercado, cada negociação é uma transação e se dão, em média, diariamente ou a cada 2 dias. Já para as transações com contrato, a negociação é feita nos termos dos contratos. Desta forma, a frequência das transações se refere aos prazos com que estes são renovados, em média, de 5 a 10 anos.

A questão da incerteza foi relatada pelos entrevistados como sendo muito similar nos dois arranjos (contratos e mercado). O principal risco (ex-post) se refere à adulteração do combustível durante o transporte ou na revenda. Nas trasações via contrato, além da incerteza pelo risco de adulteração de combustíveis, há também incertezas especificamente relacionadas à proteção dos ativos de marca e proteção de ativos específicos à transação.

O principal atributo que define a estrutura de governança é a especificidade de ativos, a qual está presente nas transações via contrato e ausente naquelas via mercado. Para melhor esclarecer a unidade de análise das especificidades dos ativos nas transações, seguem os conceitos utilizados para cada especificidade:

a) Locacional: Casos em que o posto desfruta de vantagens junto ao distribuidor por estar em localização privilegiada quanto ao fluxo de automóveis. É fato que a localização per se é característica intrínseca ao negócio de venda de combustíveis. Ressaltamos, portanto, que a existência de ativo específico locacional na transação se refere aos casos em que o agente revendedor dispõe de um privilégio de localização tal, em termos de vendas, que passa a ser alvo de interesse das distribuidoras, configurando, nesses casos, a localização como um ativo específico para a realização da transação.

b) Físicos: A existência de investimentos específicos para a transação, como adequação de equipamentos, maquinário, lay-out, dentre outras exigências na transação com a distribuidora.

c) Humanos: Quando há envolvimento de capital humano específico para a atividade, como o assessoramento dos postos por parte das distribuidoras, revelado prioritariamente pela concessão de auxílio técnico administrativo, jurídico, financeiro, ambiental, normativo etc.

d) Dedicados: Quando há realização de investimento específico à transação, com relação tal de dependência que implica inviabilidade de uso futuro em virtude do fim das transações. Estão englobados neste caso investimentos adicionais às atividades rotineiras dos postos, como sistemas integrados de informação, sistemas de controle de estoque integrados e outros benefícios conjuntos que possam minimizar custos operacionais e que são exclusivos daquela relação comercial.

e) Marca: Ativo intangível que diferencia postos bandeirados dos postos de bandeira branca.

A observação das diferentes combinações entre as especificidades dos ativos permite a identificação de vários tipos de postos revendedores, diferenciados pelas especificidades que compõem suas transações. 
A partir da análise das especificidades de ativos, os resultados sugerem para distribuidores dominantes a manutenção de uma maioria de transações estruturadas por contratos, contando de 2 a 3 ativos específicos e uma parcela mínima de transações com baixo grau de especificidades, estruturadas via mercado, com postos de bandeira branca.

Para os distribuidores regionais, é mais comum a manutenção da forma contratual com baixas especificidades de ativo, junto aos seus postos bandeirados, e uma elevada participação de transações com nenhum ativo específico com postos de bandeira branca, numa estrutura de governança de mercado.

Para os distribuidores independentes, as transações são governadas via mercado nas suas transações com postos de bandeira branca, sem qualquer especificidade de ativos.

\subsection{Formas plurais observadas}

Considerando os três tipos de distribuidores no mercado, temos a seguinte configuração da participação das diferentes estruturas de governança no negócio, conforme dados descritos no Quadro 2. Os valores de percentual no faturamento foram declarados pelos diretores entrevistados. Para cada grupo, foi considerada a menor e a maior participação para construção dos intervalos de participação das estruturas de governança no faturamento.

Podemos perceber a existência de grupos de agentes que atuam de forma plural, sendo praticamente inverso o posicionamento entre as duas estruturas de governança vigentes: mercado e contratos. A observação deste mercado indica que as grandes firmas (Dominantes) deslocam suas vendas para as transações via contrato, enquanto as distribuidoras menores (Regionais) atuam majoritariamente nas vendas via mercado. A observação do mapa da revenda no Quadro 3 confirma este comportamento.

As distribuidoras que são singulares e operam apenas sob a forma de governança de mercado, aqui denominadas de Independentes, apresentam elevado portfólio de clientes regulares e uma baixíssima participação de mercado. Dentre as empresas entrevistadas, $90 \%$ declarou não ter interesse em manter transações via contratos, por meio de franqueamento de postos revendedores.

A principal causa de desinteresse das distribuidoras Independentes diante da estrutura de governança via contratos foi justificada pelo alto investimento necessário e o baixo retorno, dada a infidelidade de compras dos postos franqueados e o baixo poder de enforcement dessas firmas diante de tais quebras contratuais.

O ambiente institucional, por sua vez, também não cumpre seu papel disciplinador no mercado, ao contrário, a morosidade da justiça brasileira representa incentivos para a prática de comportamentos oportunistas, especialmente aqueles relacionados à realização de compras fora do arranjo exclusivo de negociação; mesmo com o aumento da fiscalização nos últimos anos.

Quadro 2. Estruturas de Governança utilizadas pelas firmas distribuidoras.

\begin{tabular}{|l|c|c|c|}
\hline \multirow{2}{*}{ Tipo de Distribuidor } & \multicolumn{2}{|c|}{ Governanças utilizadas (\% no faturamento) } & \multirow{2}{*}{ Classificação } \\
\cline { 2 - 4 } & Contratos & Mercado & Plurais \\
\hline Dominantes & Entre $80 \%$ e $95 \%$ & Entre 5\% e $20 \%$ & Plurais \\
\hline Regionais & Entre 2\% e 5\% & Entre $95 \%$ e $98 \%$ & Singulares \\
\hline Independentes & - & $100 \%$ & \\
\hline
\end{tabular}

Fonte: Elaboração própria.

Quadro 3. Mapa da revenda de Gasolina - Brasil - 2010.

\begin{tabular}{|c|c|c|c|}
\hline \multicolumn{2}{|c|}{ Mercado de GASOLINA } & \multicolumn{2}{|c|}{ Mercado de ETANOL } \\
\hline FORNECEDORES & $\begin{array}{c}\text { POSTO DE } \\
\text { COMBUSTÍVEL }\end{array}$ & FORNECEDORES & $\begin{array}{c}\text { POSTO DE } \\
\text { COMBUSTÍVEL }\end{array}$ \\
\hline $\mathrm{BR}(8,7 \%)$ & \multirow{5}{*}{$\begin{array}{c}\text { BANDEIRA BRANCA } \\
\text { (32,9\% das vendas nacionais } \\
\text { de combustíveis) } \\
\text { venda média por posto: } \\
\mathbf{5 9 0 , 9} \mathbf{~ m}^{3} / \text { ano }\end{array}$} & $\mathrm{BR}(3,8 \%)$ & \multirow{5}{*}{\begin{tabular}{|c|} 
BANDEIRA BRANCA \\
(48,1\% das vendas nacionais \\
de combustíveis) \\
venda média por posto: \\
$\mathbf{4 3 6 , 3} \mathbf{~ m}^{3} / \mathbf{a n o}$
\end{tabular}} \\
\hline Ipiranga $(6,3 \%)$ & & Ipiranga $(3,0 \%)$ & \\
\hline Shell $(2,9 \%)$ & & Shell $(1,0 \%)$ & \\
\hline $\operatorname{Cosan}(3,6 \%)$ & & Cosan $(1,5 \%)$ & \\
\hline Outras $(78,5 \%)$ & & Outras $(90,7 \%)$ & \\
\hline $\begin{array}{c}\text { Distribuidores } \\
\text { bandeiradores }(100 \%)\end{array}$ & $\begin{array}{c}\text { BANDEIRADOS } \\
\text { (67,1\% das vendas nacionais } \\
\text { de combustíveis) } \\
\text { venda média por posto: } \\
\mathbf{9 5 5 , 6 ~ \mathbf { ~ m } ^ { 3 } / \text { ano }}\end{array}$ & $\begin{array}{l}\text { Distribuidores bandeiradores } \\
\qquad(100 \%)\end{array}$ & $\begin{array}{c}\text { BANDEIRADOS } \\
\text { (51,9\% das vendas nacionais } \\
\text { de combustíveis }) \\
\text { venda média por posto: } \\
\mathbf{3 7 3 , 3 4} \mathbf{~ m}^{\mathbf{3}} / \mathbf{a n o}\end{array}$ \\
\hline
\end{tabular}

Fonte: Boletim Abastecimento em números (ANP, 2011). Elaboração Própria. 
Neste sentido, os dados secundários do setor confirmam tal expectativa na medida em que os índices de infidelidade de compras ainda se mantêm altos, variando em torno de $30 \%$ a $50 \%$. Tal índice refere-se ao percentual de amostras coletadas para análise de qualidade ou consultadas no levantamento de preços, das quais não se apresenta nota fiscal comprobatória de origem. Infração do inciso III do Art. $3^{\circ}$ da Portaria ANP n 202 de 15 de agosto de 2000, que pode resultar em cancelamento da autorização da ANP ao posto revendedor.

Um agravante desta questão da infidelidade é persistência de um comércio irregular de etanol representativo. Atualmente, mais de $15 \%$ de todo etanol comercializado no País é irregular. Este percentual é a participação no total de etanol da diferença entre aquilo que é declarado pelas usinas ao MAPA (Ministério da Agricultura, Pecuária e Abastecimento) e o que é declarado pelas distribuidoras à ANP, nas vendas para postos revendedores e exportação. Ou seja, é o etanol revendido nos postos de combustíveis que saíram direto das Usinas não passando pelo elo distribuidor, prática ilegal. Desta forma, a manutenção da estrutura de governança contratual não garante benefícios de longo prazo ao franqueador, dada a elevada incerteza após a realização de grandes investimentos em ativos específicos.

Observando as firmas que são plurais, temos dois segmentos específicos. O segmento das firmas dominantes, que mantém a maioria de transações via contratos e o das Regionais, que mantém uma maioria de transações via mercado.

Dentre as Regionais, 70\% indicam planos de expansão da rede de postos, prioritariamente por meio de franqueamento de postos já atuantes no mercado (50\%) e abertura de postos próprios $(50 \%)$. A expansão da franquia tem sido lenta e gradual.

Para as Dominantes, a expansão das franquias é uma questão crucial, sendo evidente a desmotivação das empresas em manter relações com postos de bandeira branca. Segundo os entrevistados, a tendência é franquear os postos de bandeira branca com os quais se mantêm relações frequentes $(80 \%)$ e ampliar a rede de postos bandeirados, abrindo novos postos, contudo, com menor intensidade (20\%). Tanto para as Regionais quanto para as Dominantes, os motivadores para a realização desta expansão são o fortalecimento e a divulgação da marca e o aumento do volume de vendas.

Desta maneira, as indicações dos dados coletados em campo admitem certa persistência destas formas plurais, embora em meio à instabilidade. Para as Dominantes, a principal razão apontada para a manutenção de uma parcela de transações via mercado é tornar o atual posto sem contrato em posto franqueado em pouco tempo. A manutenção de formas plurais apresenta-se, portanto, como estratégia de crescimento da firma distribuidora.
De fato, sendo o objetivo das firmas dominantes o crescimento da firma e de sua rede franqueada, por que arregimentar parceiros desta forma (mantendo-se plural) ao invés de captar outros agentes que ainda não estão no mercado e abrir novos postos? No caso da distribuição de combustível no Estado de São Paulo, ganha destaque uma questão fundamental que explica a lógica econômica desta opção. Com o crescimento dos grandes centros urbanos, a legislação para estabelecimento de postos de combustíveis tornou-se extremamente restritiva, restando poucos lugares onde se permite a instalação de um posto de combustível. As leis municipais regulam a instalação da atividade de revenda de combustíveis, considerando distâncias mínimas entre estes e locais de grande aglomeração de pessoas, como escolas, hospitais, centros comerciais etc.

Assim, o posto sem contrato já instalado pode deter um ativo locacional fundamental ao negócio, sendo que a opção concorrente de um novo posto se daria em local muito menos rentável ao negócio. Ademais, trata-se de um agente que já detém certo know how e conhece bem o funcionamento do negócio.

Sendo assim, haveria uma instabilidade contínua dessas formas plurais refletidas no movimento de iniciar transações via mercado e, posteriormente, torná-las contratos de longo prazo considerados mais vantajosos ao distribuidor, já que nesses arranjos há maior controle e exercício de autoridade, reduzindo incerteza e garantido retornos associados ao ativo de marca dessas firmas tradicionais, conforme Figura 1 a seguir.

Desta forma, fica evidente que as transações via mercado não são o canal de distribuição preferido das firmas distribuidoras, embora sua persistência se mantenha tanto pela necessidade de captação de novos parceiros comerciais quanto pela detenção de ativos específicos ao negócio por parte do posto revendedor, o que faz dele foco de interesse do distribuidor e ajuda a manter a continuidade de tais transações.

Soma-se a esta questão de preferência, entre o modelo contratual em detrimento das transações via mercado, o fato de que não há sinergias positivas entre estas duas estruturas de governança. De fato, estas são concorrentes. Não haveria motivo para que os distribuidores investissem no aprofundamento das transações via mercado, se tal medida resultasse em depreciação de seu canal de vendas prioritário, qual seja a franquia.

O fortalecimento da rede de postos franqueados e dos ativos de marca do distribuidor implica a progressiva redução das participações das vendas via mercado, embora a necessidade de manutenção de uma pequena parcela de transações via mercado ainda se faça necessária como estratégia de crescimento conforme se argumentou anteriormente.

Ou seja, conforme esquema analítico da Figura 2, considera-se que, dada a concorrência acirrada entre 


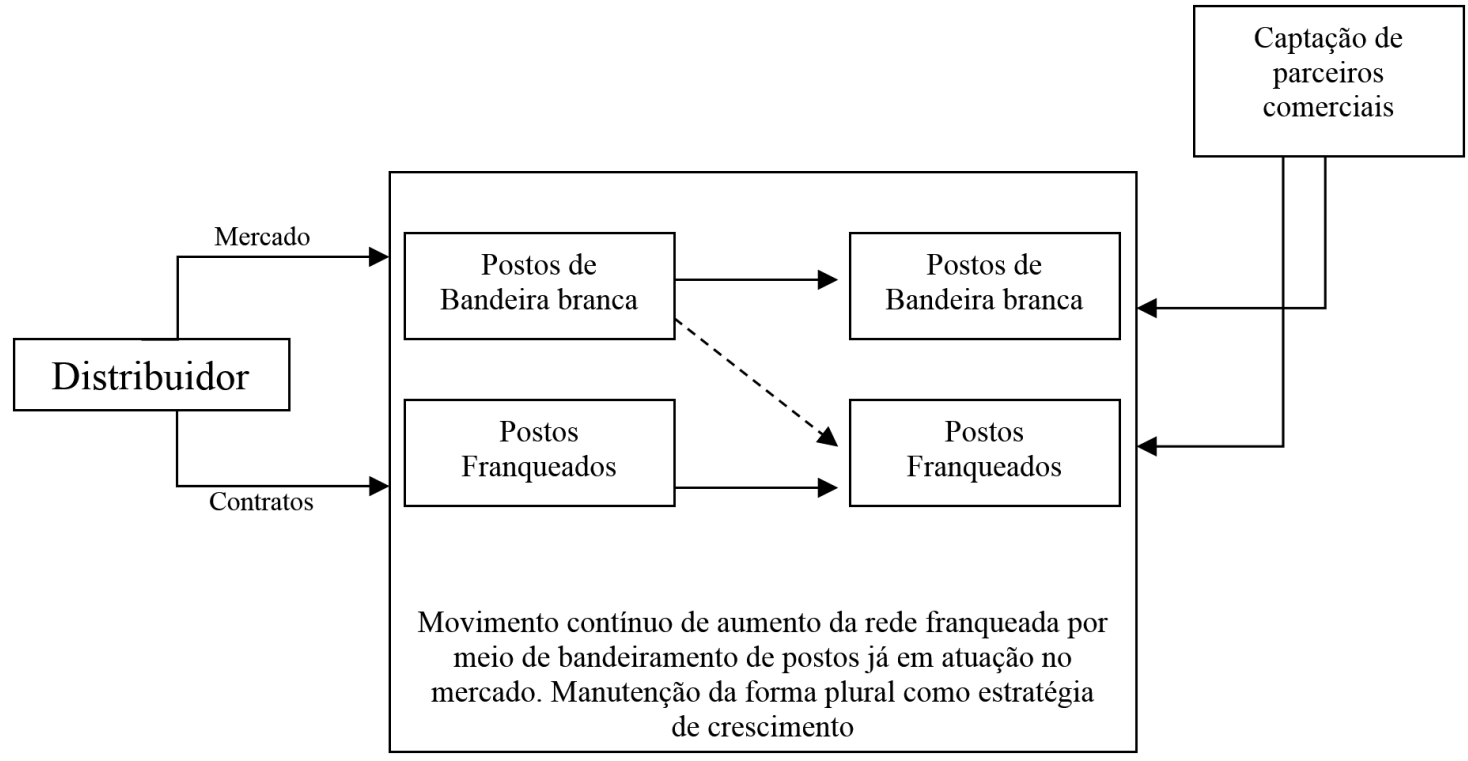

Figura 1. Estabilidade esperada para a forma plural. Fonte: Elaboração própria.

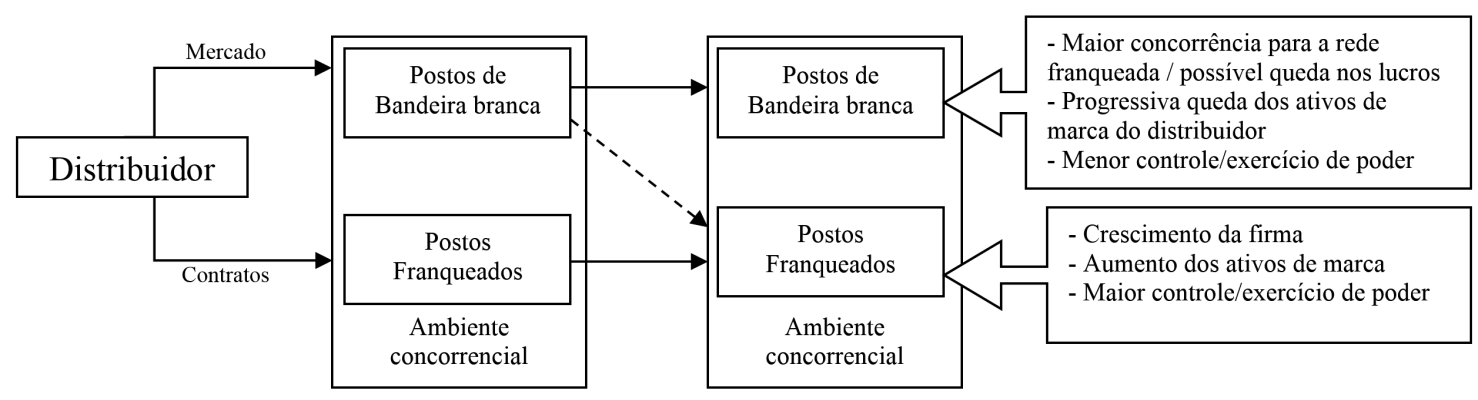

Figura 2. Resultados das formas plurais utilizadas. Fonte: Elaboração própria.

postos franqueados e de bandeira branca, não há efeito sinérgico positivo que contribua para a manutenção destes dois canais a longo prazo. A decisão de descontinuidade fortalece a governança que favorece a marca, o exercício de poder e o posicionamento estratégico ao longo da cadeia.

Ao contrário de alguns arranjos em que há retornos favoráveis na manutenção da forma plural, no mercado de distribuição de combustíveis, em que as franquias não são detentoras de grandes áreas exclusivas de vendas, como nas franquias tradicionais, aumentar a concorrência fortalecendo o canal concorrente implica perdas futuras. Especialmente, quando se considera a importância da marca nestes mercados, na medida em que é um bem com elevados custos de mensuração, e a marca passa a ser indicativo substancialmente forte nas decisões de compra do consumidor.

\section{Discussões finais}

Considerando a concentração de mercado do conjunto de empresas dominantes, pode-se concluir que a política pública que visava no fim dos anos noventa um aumento da competição do setor, incentivando o aumento das transações via mercado, não teve a repercussão desejada. Ao contrário, o movimento de concentração de mercado e o encaminhamento das transações para o modelo contratual têm sido recorrente nas empresas dominantes.

Em parte, a liberação para postos sem contratos de exclusividade no fornecimento em fins dos anos 1990 serviria ao objetivo de ter agentes operando a preços mais baixos, na medida em que não teriam as despesas de franqueamento e ofereceriam ao mercado o mesmo produto, agora, sem ostentação da marca do distribuidor. A presença destes agentes seria um instrumento de normalização do mercado reduzindo os preços. Contudo, é importante ressaltar que a entrada de tais postos (bandeira branca) no mercado se deu em meio a um ambiente institucional não regulado e sem fiscalização, junto com a entrada de centenas de novas firmas distribuidoras, operando das mais variadas formas, e também milhares de usinas de etanol não fiscalizadas.

Neste ambiente novo, muitas práticas irregulares foram facilitadas, desde sonegação de impostos até a 
adulteração de combustíveis. Esta instabilidade gerou na população consumidora temor quanto a estes novos postos sem referencial de marcas. Até hoje o consumidor considera que abastece combustível de pior qualidade nos postos de bandeira branca (Soares \& Paulillo, 2011). Atualmente os índices de não conformidade no Estado de São Paulo estão em patamares baixos e com pouca diferença entre as marcas regionais, dominantes ou bandeiras brancas, mas a memória de um período de extrema desconfiança persiste, juntamente com a consideração de que o ambiente institucional regulador ainda não cumpre seu papel.

Desta forma, é possível que o posicionamento competitivo dos postos sem contratos não seja suficiente para a atração das distribuidoras dominantes na continuidade dos negócios via mercado. Além do mais, o fortalecimento deste canal de distribuição favorece aumento da concorrência aos postos franqueados, o que poderia minar a estrutura de governança preferida pelas firmas dominantes. Assim, a decisão estratégica das empresas distribuidoras consiste em não se manter plural por mais tempo que o necessário.

\section{Agradecimentos}

Agradecimento à FAPESP (Fundação de Amparo à Pesquisa do Estado de São Paulo) pela concessão de bolsa de pós-doutorado ao primeiro autor.

\section{Referências}

Agência Nacional do Petróleo, Gás Natural e Biocombustíveis -ANP. (2011). Abastecimento em números (Vol. 3, No. 33, Boletim Gerencial Superintendência de Abastecimento). Rio de Janeiro: ANP. Recuperado em 10 de março de 2012, de www.anp.gov.br/?dw=58353.

Agência Nacional do Petróleo, Gás Natural e Biocombustíveis -ANP. (2013). Anuário estatístico 2012. Rio de Janeiro: ANP. Recuperado em 10 de março de 2014, de http:// www.anp.gov.br/?pg=62463\&m=\&t1=\&t2=\&t3=\&t4 $=\& a r=\& p s=\& 1442854636719$

Arthur, W. B. (1989). Competing technologies, increasing returns, and lock-in by historical events. The Economic Journal, 99(394), 116-131. http://dx.doi. org/10.2307/2234208.

Arthur, W. B. (1994). Increasing returns and path dependence in the economy. Ann Arbor: University of Michigan Press.

Azevedo, P. F., \& Silva, V. L. S. (2012). Os opostos se completam! Revisando a teoria econômica sobre mix contractual (ou formas plurais). In V. L. SILVA \& P. F. AZEVEDO (Orgs.), Teoria e prática do franchising: estratégia e organização de redes de franquias (Cap. 9). São Paulo: Atlas.

Bai, C. E., \& Tao, Z. (2000). Contractual mix in franchising as a mechanism for public-good provision. Journal of Economics \& Management Strategy, 9(1), 85-113. http://dx.doi.org/10.1162/105864000567800.
Barzel, Y. (1982). Measurement cost and the organization of markets. The Journal of Law \& Economics, 25(1), 27-48. http://dx.doi.org/10.1086/467005.

Bradach, J. L., \& Eccles, R. (1989). Price, authority and trust: from ideal types to plural forms. Annual Review of Sociology, 15(1), 87-118. http://dx.doi.org/10.1146/ annurev.so.15.080189.000525.

Bradach, J. L. (1997). Using the plural form in the management of restaurant chains. Administrative Science Quarterly, 42(2), 276-303.

Carlton, D. (1979). Vertical integration in competitive markets under uncertainty. The Journal of Industrial Economics, 27(3), 198-209. http://dx.doi.org/10.2307/2098317.

Coughlan, A. T., Anderson, E., Stern, L. W., \& El-Ansary, A. I. (2002). Canais de marketing e distribuição (6. ed., pp. 411-437). Porto Alegre. The Bookman.

Hart, O., \& Moore, J. (1990). A theory of corporate financial structure based on the seniority of claims (Working Papers, 560). Cambridge: Massachusetts Institute of Technology.

Heide, J. B. (2003). Plural governance in industrial purchasing. Journal of Marketing, 67(4), 18-29. http:// dx.doi.org/10.1509/jmkg.67.4.18.18689.

Lafontaine, F., \& Shaw, K. L. (2005). Targeting managerial control: evidence from franchising. The Rand Journal of Economics, 36(1), 131-150.

Lal, R. (1990). Improving channel coordination through franchising. Marketing Science, 9(4), 299-318. http:// dx.doi.org/10.1287/mksc.9.4.299.

Mahoney, J. (1992). The choice of organizational form: vertical financial ownership versus other methods of vertical integration. Strategic Management Journal, 13(8), 559-584. http://dx.doi.org/10.1002/smj.4250130802.

Marjotta-Maistro, M. C. (2002). Ajustes nos mercados de álcool e gasolina no processo de desregulamentação (Tese de doutorado). Escola Superior de Agricultura "Luiz de Queiroz”, Universidade de São Paulo, Piracicaba.

Medeiros, E. (2007). Estratégias competitivas no comércio varejista de combustiveis, segundo o modelo de Porter (Monografia). Universidade Federal de Santa Catarina, Florianópolis.

Ménard, C. (2004). The economics of hybrid organization. Journal of Institutional and Theoretical Economics, 160(3), 345-376.

Ménard, C. (2006). Hybrid organization of production and distribution. Revista de Análisis Económico, 21(2), 25-41.

Michael, S. C. (2000). Investments to create bargaining power: the case of franchising. Strategic Management Journal, 21(4), 497-514. http://dx.doi.org/10.1002/(SICI)10970266(200004)21:4<497::AID-SMJ87>3.0.CO;2-\#.

Mols, N. P., Hansen, J. R., \& Villadsen, A. R. (2012). Plural governance: the effect of internal production on supplier performance. Industrial Marketing 
Management, 41(5), 874-885. http://dx.doi.org/10.1016/j. indmarman.2011.09.022.

Mols, N. P. (2010). Economic explanation for concurrent sourcing. Journal of Purchasing \& Supply Management, 16(1), 61-69.

Moraes, M. A. F. D. (2004). A cadeia produtiva da cana, em mercado desregulamentado. Revista Visão Agrícola, 1(1), 94-99.

Nunes, C., \& Gomes, C. (2005). Aspectos concorrenciais do varejo de combustíveis no Brasil, In Anais do XXXIII Encontro Nacional de Economia. Natal: ANPEC. Recuperado em 20 de fevereiro de 2014, de http:// www.anpec.org.br/encontro2005/artigos/A05A108.pdf.

Parmigiani, A. (2007). Why do firms both make and buy? An investigation of concurrent sourcing. Strategic Management Journal, 28(3), 285-311. http://dx.doi. org/10.1002/smj.580.

Schnaider, P. S. B. (2011). Formas plurais e assimetrias de informação (Dissertação de mestrado). Faculdade de Economia, Administração e Contabilidade, Universidade de São Paulo, São Paulo.

Sindicato Nacional das Empresas Distribuidoras de Combustíveis e de Lubrificantes - SINDICOM. (2014).
Combustiveis, lubrificantes \& lojas de conveniência 2013. Rio de Janeiro: SINDICOM.. Recuperado em 20 de fevereiro de 2014, de http://www.sindicom.com.br/ download/anuario_sindicom_2013_FINAL_revisado.pdf.

Soares, S. S. S. (2012). Distribuição de combustiveis no estado de São Paulo: estruturas de governança no setor de distribuição e quebras de contrato (Tese de doutorado). Departamento de Engenharia de Produção, Universidade Federal de São Carlos, São Carlos.

Soares, S. S. S., \& Paulillo, L. F. (2011). Economia dos custos de mensuração e a percepção do consumidor sobre postos de combustíveis no estado de São Paulo. In Anais do XXXI Encontro Nacional de Engenharia de Produção. Belo Horizonte: ENEGEP.

Williamson, O. E. (1979). Transaction cost economics: the governance of contractual relations. Journal of Law and Economics, 22(2), 233-261.

Williamson, O. E. (1985). The economic institutions of capitalism. New York: The Free Press. 450 p.

Williamson, O. E. (1991). Comparative economic organization: the analysis of discrete structural alternatives. Administrative Science Quarterly, 36(2), 269-296. 